\title{
New Constraints on Methane Fluxes and Rates of Anaerobic Methane Oxidation in a Gulf of Mexico Brine Pool via In Situ Mass Spectrometry
}

\section{Citation}

Wankel, Scott D., Samantha B. Joye, Vladimir A. Samarkin, Sunita Rajesh Shah, Gernot Friederich, John Melas-Kyriazi, and Peter R. Girguis. 2010. New constraints on methane fluxes and rates of anaerobic methane oxidation in a Gulf of Mexico brine pool via in situ mass spectrometry. Deep Sea Research Part II: Topical Studies in Oceanography 57(21-23): 2022-2029.

\section{Published Version}

doi:10.1016/j.dsr2.2010.05.009

\section{Permanent link}

http://nrs.harvard.edu/urn-3:HUL.InstRepos:10136320

\section{Terms of Use}

This article was downloaded from Harvard University's DASH repository, and is made available under the terms and conditions applicable to Open Access Policy Articles, as set forth at http:// nrs.harvard.edu/urn-3:HUL.InstRepos:dash.current.terms-of-use\#OAP

\section{Share Your Story}

The Harvard community has made this article openly available.

Please share how this access benefits you. Submit a story.

Accessibility 
1 New constraints on methane fluxes and rates of anaerobic methane oxidation in a Gulf of Mexico brine pool via in situ mass spectrometry

Scott D. Wankel ${ }^{1}$, Samantha B. Joye ${ }^{2}$, Vladimir A. Samarkin ${ }^{2}$, Sunita R. Shah ${ }^{3}$, 8 Gernot Friederich $^{4}$, John Melas-Kyriazi ${ }^{5}$, and Peter R. Girguis ${ }^{1^{*}}$

${ }^{1}$ Department of Organismic and Evolutionary Biology, Harvard University, Cambridge, MA 02138.

${ }^{*}$ Corresponding author: pgirguis@oeb.harvard.edu

${ }^{2}$ Department of Marine Sciences, University of Georgia, Athens, GA 30602-3636

${ }^{3}$ US Naval Research Laboratory, Washington DC 20375

${ }^{4}$ Monterey Bay Aquarium Research Institute, Moss Landing, CA

${ }^{5}$ Stanford University, Stanford, CA 94305 
Deep sea biogeochemical cycles are, in general, poorly understood due to the

48 difficulties of making measurements in situ, recovering samples with minimal

49 perturbation and, in many cases, coping with high spatial and temporal heterogeneity. In

50 particular, biogeochemical fluxes of volatiles such as methane remain largely

51 unconstrained due to the difficulties of accurate quantification in situ and the patchiness

52 of point sources such as seeps and brine pools. To better constrain biogeochemical fluxes

53 and cycling, we have developed a deep sea in situ mass spectrometer (ISMS) to enable

54 high-resolution quantification of volatiles in situ. Here we report direct measurements of

55 methane concentrations made in a Gulf of Mexico brine pool located at a depth of over

$562300 \mathrm{~m}$. Concentrations of up to $33 \mathrm{mM}$ methane were observed within the brine pool,

57 while concentrations in the water directly above were three orders of magnitude lower.

58 These direct measurements enable the first accurate estimates of the diffusive flux from a

59 brine pool, calculated to be $1.1 \pm 0.2 \mathrm{~mol} \mathrm{~m}^{-2} \mathrm{yr}^{-1}$. Integrated rate measurements of

60 aerobic methane oxidation in the water column overlying the brine pool were $\sim 320 \mu \mathrm{mol}$

$61 \mathrm{~m}^{-2} \mathrm{yr}^{-1}$, accounting at most for just $0.03 \%$ of the diffusive methane flux from the brine

62 pool. Calculated rates of anaerobic methane oxidation were 600 to $1200 \mu \mathrm{M} \mathrm{yr}^{-1}$, one to

63 two orders of magnitude higher than previously published values of AOM in anoxic

64 fluids. These findings suggest that brine pools are enormous point sources of methane in

65 the deep sea, and may, in aggregate, have a pronounced impact on the global marine

66 methane cycle. 


\section{Introduction}

\subsection{Global importance of methane}

The marine methane cycle has been the subject of much investigation in recent

70 years, in large part due to burgeoning interest and concern over deep ocean methane

71 hydrates. The deep ocean methane reservoir represents an enormous and dynamic pool

72 of carbon likely exceeding reserves of conventional oil and gas (Collett and Kuuskraa,

73 1998). In deep ocean regions, characterized by low temperatures, high pressure and

74 sufficient methane concentration, methane exists largely in the solid form of a gas

75 hydrate (Kvenvolden, 1993). Methane seeps and associated gas hydrates have been

76 identified along many passive and active continental margins (Kvenvolden and Lorensen,

77 2008). Because the destabilization of hydrates is sensitive to increases in temperature or

78 decreases in pressure, it has been postulated that increases in mean global temperatures

79 might trigger a release of methane into the ocean and atmosphere. A significant release

80 of methane into the atmosphere could ultimately lead to a catastrophic greenhouse effect;

81 this mechanism has been invoked as an explanation for past deglaciation events (Dickens,

82 2003; Sloan et al., 1992; Zachos et al., 2001).

83 Despite recent, numerous studies of methane hydrates, modern fluxes of methane

84 from the deep sea into surface waters and ultimately the atmosphere are very poorly

85 constrained. Estimates of methane flux have been aided, to some degree, by recent

86 advances in our understanding of marine microbiological influences on the global

87 methane cycle. Aspects of the marine methane cycle remain largely unconstrained due to

88 limitations in methods and technologies that enable accurate assessment of methane 
89 concentration and flux - as well as rates of biological methanogenesis or methanotrophy.

90 Pressure and temperature have a pronounced effect on methane solubility. As such,

91 upon retrieval of methane-saturated waters or hydrate-rich sediments from the deep

92 ocean, methane rapidly outgasses to the atmosphere. Thus, it has been challenging to

93 constrain flux and microbial activity in situ, under environmentally relevant conditions.

94 Because previous data have shown that methane oxidation, both aerobic and anaerobic,

95 are the largest methane sinks in marine environments (Reeburgh, 2007), understanding

96 what controls methane oxidation -including concentration and abiotic flux- are paramount

97 to understanding global methane dynamics.

98 To better constrain the methane flux in chemically reducing environments - and

99 ultimately to quantify the influence of biotic and abiotic processes on the methane cycle -

100 we employed a newly developed in situ mass spectrometer (ISMS) to conduct direct

101 measurements of methane concentration which - in concert with shipboard

102 microbiological measurements - were used to generate more robust estimates of diffusive

103 flux and net methane oxidation rates in a newly discovered brine pool in the Gulf of

104 Mexico.

\section{2. Geologic Setting}

106 Along the continental shelf in the Gulf of Mexico, massive reservoirs of liquid

107 and gaseous hydrocarbons lie buried beneath kilometers of sediment accumulated from

108 the Mississippi River drainage basin. Due to compression and dewatering of the

109 overlying sediments, underlying evaporite deposits have undergone plastic deformation

110 resulting in salt-diapir driven tectonic activity (Kennicutt et al., 1988). The resulting

111 system of fractures and faults provides conduits for the emission of hydrocarbons to the 
112 seafloor via seepage (Roberts and Carney, 1997). Hydrocarbon seeps are often

113 characterized by abundant chemosynthetic based macro- and microfaunal communities

114 including tubeworms, mussel beds, and bacterial mats which thrive on the reduced

115 organic compounds emanating from below (Fisher et al., 2007; MacDonald et al., 1990;

116 MacDonald et al., 2003). In addition, hypersaline brine fluids seep from the seafloor in

117 many locations (MacDonald et al. 1990; Joye et al. 2005, 2009). Previous studies have

118 provided insight into the geochemical composition of these brine pools, though to date

119 volatile flux and net rates of methane oxidation remain poorly constrained due to the

120 challenges in quantification resulting from off-gassing (at in situ pressures and

121 temperatures relevant here, methane saturation is $\sim 174 \mathrm{mmol} \mathrm{kg}^{-1}$ (Duan and Mao,

122 2006)). Accurate sampling of fluids with high gas content using conventional methods

123 (e.g., Niskin Bottles) has thus proven impractical for volatiles.

124 The brine pool characterized in this study (AC601) is located in the Alaminos

125 Canyon lease block $601\left(26^{\circ} 23.53 \mathrm{~N} ; 94^{\circ} 30.85 \mathrm{~W}\right.$; Roberts et al. this issue; (Roberts et

126 al., 2007). The brine pool is estimated to be $\sim 250 \mathrm{~m}$ in diameter and approximately 2334

127 meters below sea surface. This brine pool was visited during expeditions on board the

128 RV Ronald H. Brown using the DSV Jason II during expeditions from May 6 through

129 June 4, 2006 and June 3 through July 6, 2007 (see Roberts et al., this issue), for further

130 description of the expeditions and site locations). Discrete geochemical measurements of

131 this brine pool were made during the 2006 and 2007 expedition, while deployment of the

132 ISMS was carried out during the 2007 expedition. 


\section{3. Methods}

\section{3.1. Fundamentals of Membrane Inlet Mass Spectrometry/ISMS}

135 Over the past five decades, the use of membrane inlet mass spectrometry (MIMS)

136 has proven to be a powerful tool for measuring complex mixtures of dissolved gases in

137 both industrial and laboratory settings (Johnson et al., 2000; Ketola et al., 2002). MIMS

138 represents an optimal technique for mixed environmental gas analysis, having a high

139 degree of sensitivity and precision, with minimal sample perturbation (Kana et al., 1994).

140 MIMS has been used over the past several decades to measure and monitor a wide range

141 of dissolved gases in aquatic and terrestrial environments, including studies of bacterial

142 mats, peat bogs, estuarine sediments, forest soils, and tree canopies to name a few

143 (Hemond, 1991; Kana et al., 1998; Lloyd et al., 1986; Lloyd et al., 1998). MIMS has

144 also been used to study metabolite flux during shipboard high-pressure experiments (e.g.,

145 (Girguis et al., 2002; Girguis et al., 2000). MIMS has also emerged as an important tool

146 for analyzing dissolved gases in seawater, (e.g. dissolved gases in surface waters

147 analyzed continuously shipboard;(Kaiser et al., 2005; Tortell, 2005a; Tortell, 2005b) and

148 more recently for in situ marine surface waters (Bell et al., 2007; Camilli and Hemond,

149 2004; Kaiser et al., 2005; Tortell, 2005b, c).

150 The recent adaptation of MIMS to in situ environmental analyses demonstrates

151 the utility of such an instrument operating while underway at sea - allowing the continual

152 monitoring of many gas species in real time. This approach allows highly accurate

153 monitoring of spatially explicit biogeochemical changes. For example, changes in $\mathrm{O}_{2} / \mathrm{Ar}$

154 indicate changes in net community production in ocean surface waters in different

155 regions of the eastern equatorial Pacific (Kaiser et al., 2005). Additionally, $\mathrm{N}_{2} / \mathrm{Ar}$ has 
156 been used to identify areas of active denitrification (e.g., $\mathrm{N}_{2}$ production) in seasonally

157 oxygen-depleted bottom waters via MIMS in Saanich Inlet (Tortell, 2005b). Underway

158 shipboard trace gas analysis has also shed light on dynamics of dimethylsulfide (Tortell, 159 2005a).

160 Given the apparent utility of real-time quantification by MIMS, we aimed to

161 develop a MIMS that would achieve comparable performance in waters deeper than 1000

162 meters. Currently, investigation of deep water samples still generally requires the

163 collection of individual samples and shipboard analysis (e.g., Tortell, 2005b), risking

164 contamination and/or degassing. Furthermore, individual sample collection and analysis

165 can often result in delays between sampling and data interpretation. Our understanding

166 of deep-sea biogeochemistry would greatly benefit from real-time, in situ dissolved gas

167 analysis. Here we present results from a real-time in situ membrane inlet mass

168 spectrometer designed to A) operate at depths up to 450 atmospheres of pressure, B)

169 provide real-time data to the user (when used on human occupied submersibles or

170 remotely operated vehicles), and C) enable sampling with high spatial and temporal

171 resolution using an in situ pumping system.

\section{$172 \quad$ 3.2. ISMS Design and Calibration}

173 This ISMS consisted of three primary sub-systems: 1) a high-pressure membrane

174 inlet (Fig. 1a) with a small volume seawater pumping system;, 2) a quadrupole mass

175 spectrometer (Fig. 1e, f) and oil-less vacuum pumping system (Fig. 1 d, g); and 3) an

176 underwater housing (either a 2000 meter-rated aluminum 3300 alloy housing, or a 4500

177 meter rated 6AL-4V titanium housing, both of which are approximately $120 \mathrm{~cm}$ in length

178 and $24 \mathrm{~cm}$ in diameter). The membrane inlet assembly consisted of a circular sheet 
179 (0.625 in. diameter) of polydimethylsiloxane (PDMS) membrane structurally backed by

180 an integrated woven fiber (Franatech, Germany). This pliable membrane material was

181 supported by a sintered stainless steel frit ( $5 \mu \mathrm{m}$ pore size, Applied Porous Materials,

182 Tariffville, CT), which was in turn supported by the titanium body of the inlet housing.

183 Sample water was pumped through the inlet housing assembly ( $2 \mathrm{ml}$ internal volume) at a

184 flow rate of $\sim 3 \mathrm{ml} / \mathrm{min}$ using a small solenoid pump (The Lee Company, Westbrook, CT),

185 which was controlled by an adjustable timing circuit located inside of the pressure

186 housing.

187 The membrane assembly was connected to a Stanford Research Systems Residual

188 Gas Analyzer (SRS RGA100) via standard vacuum flanges. Within the vacuum system,

189 a pressure of $\sim 10 \mathrm{e}^{-5}$ Torr was maintained by a turbo-molecular pump (model: ATH 31+;

190 Alcatel, France) backed by a diaphragm roughing pump (model: ANDC83.4; KNF-

191 Neuberger, Trenton, NJ). Open source electron impact ionization was carried out with a

192 thoriated iridium wire filament. The mass spectrometer and pumps were protected from

193 membrane failure by a high-pressure / high-vacuum solenoid valve (Circle Seal, Inc.,

194 Corona, CA), which is actuated upon intrusion of water. The entire mass spectrometer

195 assembly was housed in one of the aforementioned housings. 24 VDC power and two

196 independent RS-232 channels (for serial communications with the turbo pump control

197 board and continuous feedback from the RGA analyzer) were supplied via a wet-connect

198 underwater cable (SubConn, Inc., North Pembroke, MA). In this configuration, real time

199 monitoring of fluid chemistry is achievable during submersible or ROV operations,

200 which allows for informed site selection for fluid measurements as well as adaptive

201 sampling of biological specimens. 
204 the membrane surface at various flow rates and pressures. Hydrostatic pressure against

205 the membrane inlet was manually controlled with a backpressure valve (StraVal Valve,

206 Garfield, NJ) and monitored with high pressure gauges. Various calibration solutions

207 were used including air-sparged DI water or seawater, degassed distilled water and/or

208 seawater equilibrated with gas mixtures of interest (e.g., $\mathrm{CH}_{4}$ ), including the use of a high

209 pressure equilibration system for generating very high $\mathrm{CH}_{4}$ concentrations (Fig. 2). A

210 gas chromatograph (HP 5890 Series II plus with a TCD) outfitted with a custom gas

211 extractor (Childress et al., 1984) designed for quantification of rapidly degassed seawater

212 samples was used to obtain independent analyses of dissolved methane concentrations,

213 while previously described equations of state were used to calculate dissolved methane

214 concentrations at very high pressures (Duan and Mao, 2006) (Fig. 2b). During lab

215 experiments, relative changes in signal intensity were proportional to changes in the

216 permeation of gas through the membrane (either due to changes in permeate

217 concentration or changes in the permeability coefficient). We and others have observed

218 that changes in hydrostatic pressure can have an influence on permeation of gases

219 through membrane materials, in particular PDMS, interpreted to be caused by

220 compression of the membrane pore space through which analyte gas passes (Bell et al.,

221 2007). A change in the relationship between dissolved gas concentration and signal

222 intensity was observed during large changes in hydrostatic pressure (Fig. 2a). To account

223 for this response, we conducted calibrations using methane dissolved in seawater over a

224 range of in situ pressures and used these results to develop an empirical correction as 
225 previously described (Bell et al., 2007). While this approach corrects for implicit

226 changes in membrane behavior, it should be noted that the ISMS dataset presented here is

227 comprised entirely of fluids sampled at a relatively constant depth $(\sim 2330 \mathrm{~m} \pm 2(233$

228 bar)) and temperature and as such effects due to differential pressure or temperature

229 among the samples collected were negligible. Based on benchtop calibrations, the

230 accuracy of the ISMS methane concentrations in the configuration described here was \pm

$23111 \%$, primarily due to the correction required for the pressure effects on the PDMS

232 membrane (accuracy is improved through the use of alternate membrane material (e.g.

233 Teflon AF)). Notably, however, the precision of the ISMS measurements is much better

234 than this and, based on benchtop calibrations, is within $\pm 1 \%$.

235 3.3. Water Column Methane and Oxygen Concentration

236 To determine brine pool and seawater column methane concentrations, a CTD

237 rosette was lowered into the brine pool, using sonar to identify the brine pool as the

238 rosette approached the bottom. Niskin bottles were tripped during descent to prevent

239 contamination of bottles as gas came out of solution during the rosette's ascent. Two

240 bottles were tripped in the brine pool itself, while two were tripped 1 meter above the

241 brine-seawater interface (the interface was confirmed by the real-time conductivity

242 signal). After securing the rosette on deck, water samples were immediately transferred

243 to 1-liter PET-G bottles using gas-impermeable tubing. Bottles that were tripped in the

244 brine were substantially over-pressured and not suitable for gas quantification (though

245 samples were transferred to the PET-G bottles for rate measurements). A second sample

246 was transferred to a $250 \mathrm{~mL}$ BOD bottle for determination of dissolved oxygen using a

247 high sensitivity Orion ${ }^{\circledR}$ oxygen electrode. Methane was extracted using an adaptation of 
248 the sonication/vacuum extraction technique (Suess et al., 1999) followed by gas

249 chromatography for quantification. Prior to dissolved gas extraction, samples were

250 stored at bottom water temperature $\left(4^{\circ} \mathrm{C}\right)$. Two individual samples were analyzed from

251 each rosette bottle.

252 3.4. ISMS Deployments and Determining Brine Pool Methane Concentrations

253 Upon reaching the brine pool, the submersible took care not to disturb the brine-

254 seawater interface. Using the ROV manipulator, the ISMS sample inlet was positioned

255 and held in place until the ISMS response reached steady state from which in situ

256 concentrations of $\mathrm{CH}_{4}$ were calculated. A total of five independent sets of measurements

257 were made, beginning with two just above the brine fluid and three at depths of

258 approximately 5, 20 and $80 \mathrm{~cm}$ into the fluid (Figs. 3 and 4).

259 3.5. Methane Oxidation Rates

260 Aerobic methane oxidation occurs according to the following stoichiometry:

$261 \quad \mathrm{CH}_{4}+2 \mathrm{O}_{2} \rightarrow \mathrm{HCO}_{3}{ }^{-}+\mathrm{H}^{+}+\mathrm{H}_{2} \mathrm{O}$

262 Accordingly, aerobic methane oxidation rates were determined by incubating samples

263 with $\mathrm{C}^{3} \mathrm{H}_{4}$ and tracking the production of ${ }^{3} \mathrm{H}_{2} \mathrm{O}$ (Carini et al., 2005; Valentine et al.,

264 2001). Typically, triplicate live and dead (Hg killed; i.e. samples were amended with

$265 \mathrm{HgCl}_{2}$ to arrest all biological activity) samples from each depth were incubated for 36

266 hours at in situ temperatures. Unreacted $\mathrm{C}^{3} \mathrm{H}_{4}$ tracer was removed by purging samples

267 with water-saturated $\mathrm{CH}_{4}$ and the oxidation product, ${ }^{3} \mathrm{H}_{2} \mathrm{O}$, was quantified by liquid

268 scintillation counting (Carini et al., 2005). 
In general, marine anaerobic methane oxidation in hydrocarbon seeps and brine

270 pools is coupled to sulfate reduction, with the net reaction:

$$
\mathrm{CH}_{4}+\mathrm{SO}_{4}{ }^{2-} \rightarrow \mathrm{HCO}_{3}^{-}+\mathrm{HS}^{-}+\mathrm{H}_{2} \mathrm{O}
$$

272 Anaerobic methane oxidation rates were also determined by incubating samples with

$273{ }^{14} \mathrm{CH}_{4}$ and tracking the production of ${ }^{14} \mathrm{CO}_{2}$ (as in Joye et al., 1999; Valentine et al.,

274 2001). Triplicate live and dead (Hg killed) samples from the surface $(\sim 20 \mathrm{~cm})$ and sub-

275 surface $(\sim 100 \mathrm{~cm})$ brine were incubated for 48 hours at in situ temperatures. Unreacted

$276{ }^{14} \mathrm{CH}_{4}$ tracer was removed by purging with water-saturated $\mathrm{CH}_{4}$ and the ${ }^{14} \mathrm{CO}_{2}$ oxidation

277 product was quantified following acid extraction and trapping on a phethylamine wick,

278 followed by liquid scintillation counting (Carini et al., 2005).

\section{$279 \quad$ 3.6. $\quad$ Sulfate Reduction Rates}

280 Samples for sulfate reduction were collected into gas tight glass tubes, amended

281 with radiotracer $\left({ }^{35} \mathrm{SO}_{4}{ }^{2-}\right)$ and incubated for 24 hours (as in Joye et al., 2004; Orcutt et al., 282 2005). For each depth, triplicate samples were incubated along side controls (killed at 283 time zero). After incubation, samples were transferred from the tubes to $50 \mathrm{ml}$ centrifuge 284 tubes and mixed with $20 \%$ zinc acetate. Samples were processed and rates calculated as 285 presented in Orcutt et al. (2005).

\section{$286 \quad 3.7 . \quad$ Major Ion chemistry}

287 Concentrations of major ions $\left(\mathrm{SO}_{4}{ }^{2-}, \mathrm{Cl}^{-}\right.$, dissolved inorganic carbon (DIC), 288 dissolved organic matter (DOC and DON) and dissolved inorganic nitrogen $\left(\mathrm{NH}_{4}^{+}, \mathrm{NO}_{2}^{-}\right.$

289 and $\mathrm{NO}_{3}{ }^{-}$) were determined using previously reported methods (see (Joye et al., 2004)

290 and Joye et al. this volume and references therein). 


\subsection{General geochemical composition of brine pool AC601}

293 Geochemical data on the waters collected from the brine pool are given in Table

294 1. The waters of the brine pool were anoxic $\left(\mathrm{O}_{2}<2 \mu \mathrm{M}\right)$ with a $\mathrm{pH}$ of $\sim 6.3$. Salinities

295 were substantially elevated above seawater at 82 and 92 for the 20 and $100 \mathrm{~cm}$ depths,

296 respectively, with chloride measuring 1366 and $1533 \mathrm{mM}$ at each depth. Water from

297 both depths was highly enriched in dissolved inorganic carbon (DIC; $11.2 \mathrm{mM}$ at $20 \mathrm{~cm}$,

$29812.8 \mathrm{mM}$ at $100 \mathrm{~cm}$ ). Sulfate concentrations were lower than seawater, decreasing with

299 depth into the pool (Fig 4). Dissolved inorganic nitrogen was dominated by very high

$300 \mathrm{NH}_{4}{ }^{+}\left(1750\right.$ and $2195 \mu \mathrm{M}, 20$ and $100 \mathrm{~cm}$, respectively), with $\mathrm{NO}_{3}{ }^{-}$disappearing sharply

301 in the top meter of the brine. The dissolved organic matter content was also high with a

302 low $\mathrm{C}: \mathrm{N}$ of $\sim 4.6$ suggesting the importance of autochthonous production within the brine 303 waters.

\section{4.2. Water Column and Brine Pool $\mathrm{CH}_{4}$ Oxidation and $\mathrm{SO}_{4}^{-2}$ Reduction Rates}

305 Aerobic methane oxidation rates measured in the water column above the brine

306 pool from depths of $300 \mathrm{~m}$ to $2313 \mathrm{~m}$ (or heights above the brine pool from 0 to $2013 \mathrm{~m}$ )

307 ranged from 0.00 to $6.33 \pm 0.9 \mathrm{pmol} \mathrm{L}^{-1} \mathrm{~d}^{-1}$ (hereafter $\mathrm{pM} \mathrm{d}^{-1}$ ) (Fig 4). The aerobic

308 methane oxidation rate in the sample taken from directly above $(\sim 3 \mathrm{~m})$ the brine pool

309 (2328m) was significantly higher, $129.6 \pm 18.2 \mathrm{pM} \mathrm{d}^{-1}$, than rates at any other depth.

310 Using the methane concentrations determined via gas chromatography and the

311 empirically derived oxidation rates, we calculate an integrated methane oxidation rate in

312 the water column above the brine pool of $320 \mu \mathrm{mol} \mathrm{m}^{-2} \mathrm{yr}^{-1}$ 
Within the brine pool, two samples $(20 \mathrm{~cm}$ and $100 \mathrm{~cm})$ were retrieved and used

314 for sulfate reduction and anaerobic oxidation of methane (AOM) rate measurements

315 (Table 2). Methane concentrations measured in the bottles used for the rate

316 measurements were 454 and $1320 \mu \mathrm{M}$, respectively (Table 1), giving rates at these depths

317 of $78.8 \pm 7.6$ and $62.1 \pm 13.1 \mathrm{nmol} \mathrm{L}^{-1} \mathrm{~d}^{-1}$, respectively. Sulfate concentrations in the

318 brine were depleted relative to seawater with concentrations of 20 and $16 \mathrm{mM}$ at $20 \mathrm{~cm}$

319 and $100 \mathrm{~cm}$, respectively. Sulfate reduction rates were 107 and 50 nmoles per liter per

320 day (hereafter $\mathrm{nM} \mathrm{d}^{-1}$ ) at $20 \mathrm{~cm}$ and $100 \mathrm{~cm}$, respectively, and were comparable to the rates

321 of AOM on a per mole basis. As mentioned above, these oxidation rates were measured

322 using water taken from CTD rosette bottles, which, when sampling gas-charged waters,

323 are subject to outgassing and gas phase exchange during recovery. Thus, these rates are

324 considered to be conservative estimates of anaerobic methane oxidation. In situ methane

325 oxidation rates are expected to be higher as methane concentrations increase (i.e., on a

326 first order basis up to $\mathrm{k}_{\max }$ ) and are calculated below.

\section{4.3. Water Column and Brine Pool Methane Concentrations}

328 Methane concentrations measured in the water column (Fig 4) directly above the

329 brine pool ranged from 30nM to 70nM at depths between 2000 and 300m, representing

330 concentrations that were 15 to 32 times that of atmospheric equilibrium and underscoring

331 the transport of methane from below. At depths below $2000 \mathrm{~m}$, closer to the brine pool,

332 concentrations increased sharply and ranged from $111 \mathrm{nM}$ to $24 \mu \mathrm{M}$. Methane

333 concentrations, as measured by the ISMS approximately $5 \mathrm{~cm}$ above the brine

334 fluid/seawater interface near the shore of the pool and $1 \mathrm{~cm}$ above the brine

$335 \mathrm{fluid} /$ seawater interface in the center of the brine pool were 180 and $590 \mu \mathrm{M}$, 
336 respectively. Approximately $1 \mathrm{~m}$ above the brine surface, the ISMS-measured methane

337 concentration was approximately $\sim 35 \mu \mathrm{M}$, which is in general agreement with the

338 methane concentrations measured in the CTD rosette at this depth $(24 \mu \mathrm{M}$, well below

339 the saturation of methane at one atmosphere, so these particular Niskin measurements are

340 not compromised by off gassing, see Fig. 4). Concentrations at depths of 5, 20 and $80 \mathrm{~cm}$

341 into the brine fluid near the center of the pool were orders of magnitude higher (Fig 4)

342 with values of $14.3,20.3$ and $33.3 \mathrm{mM}$, respectively $( \pm 2 \%)$, and more than an order of

343 magnitude in excess of concentrations measured with Niskin sampling (see Table 1).

\section{5. Discussion}

\section{5.1. In situ rates of brine pool anaerobic methane oxidation}

346 The in situ rates of AOM reported here exceed values in other anoxic waters by at

347 least one to two orders of magnitude. Our measured rates of AOM from two sampling

348 depths allowed calculation of first order rate constants of 0.063 and $0.017 \mathrm{yr}^{-1}$ from

349 depths of $20 \mathrm{~cm}$ and $80 \mathrm{~cm}$, respectively. Coupling the in situ methane concentration

350 measurements from the ISMS to the aforementioned rate constants yields estimates of the

351 actual rates of AOM of $1285 \pm 125$ and $572 \pm 121 \mu \mathrm{M} \mathrm{yr}^{-1}$ at the depths of 20 and $80 \mathrm{~cm}$

352 in the brine pool, respectively. To the best of our knowledge, these AOM rates are by far

353 the highest documented in an anoxic water body. Whereas there has been some evidence

354 that AOM is inhibited by high chloride concentrations (e.g.,(Joye et al., 2009; Oren,

355 2002)), our data (Tables 1 and 2) suggest that moderately high salinities may in fact not

356 be inhibitory to AOM and that coupled sulfate reduction and AOM may yet play an

357 important role in many Gulf of Mexico hydrocarbon/brine environments. 
359 concentrations of methane, and the highest rates are generally found within sediments,

360 particularly hydrate-influenced sediments (e.g., (Devol, 1983; Girguis et al., 2003; Joye

361 et al., 2004; Reeburgh, 1980)). Indeed, far fewer studies have measured AOM occurring

362 in anoxic water columns, and the rates reported in these studies are generally much lower

363 than sediment rates (as is the case with most biogeochemical processes primarily due to

364 microbial density being substantially higher in sediments). Rates of AOM measured in

365 the anoxic waters of the Cariaco Basin $\left(\sim 1.5 \mu \mathrm{M} \mathrm{yr}^{-1}\right.$; Ward et al., 1987), Saanich Inlet

366 (7.3 $\mu \mathrm{M} \mathrm{yr}^{-1}$; Ward et al., 1989) and the Black Sea $\left(0.6 \mu \mathrm{M} \mathrm{yr}^{-1}\right.$; Reeburgh et al., 1991)

367 were all orders of magnitude lower than those observed in this study. Joye et al (1999)

368 measured rates as high as $17.5 \mu \mathrm{M} \mathrm{yr}^{-1}$ in the bottom waters of alkaline, saline Mono

369 Lake. Notably, these rates were measured during a period when the lake waters were

370 well mixed. More recent data collected during a period of extended meromixis in Mono

371 Lake exhibit substantially higher rates of AOM (up to $365 \mu \mathrm{M} \mathrm{yr}^{-1}$ ) (Joye et al.,

372 submitted).

373 The rates of AOM presented here are also consistent with the extremely high in

374 situ concentrations occurring at these depths. Turnover times of methane in the anaerobic

375 brines were on the order of 16 to 58 years, more than long enough to maintain supply of

$376 \mathrm{SO}_{4}^{-2}$ via diffusion. Such long turnover times also might suggest that supply to the

377 overlying water via diffusion is likely to be a substantial methane sink relative to removal

378 by AOM (or aerobic oxidation at the brine-seawater interface) in similar brine pool

379 environments. Indeed, given that the rate constants were lower than many other

380 comparable environments, the rates presented represent a conservative estimate and, as 
381 previously mentioned, the rate constants would likely increase at the higher methane

382 concentrations found in situ.

\section{5.2. Estimates of $\mathrm{CH}_{4}$ flux from the brine pool}

384 Research on deep-sea fluxes and transformations of biological compounds is

385 constantly challenged by the need to sample at extreme temperatures, depths and

386 pressures. Measurement of these compounds in situ provides more rigorous constraints

387 on their fluxes and transformation rates. In the context of the current study, the in situ

388 mass spectrometer allowed direct measurement of methane concentrations in a gas-

389 charged brine pool. These concentration measurements were used to calculate a diffusive

390 flux of methane from the brine pool into the overlying water column of $1.1 \pm 0.2 \mathrm{~mol} \mathrm{~m}^{-2}$

$391 \mathrm{yr}^{-1}$, illustrating the magnitude of methane flux from benthic environs into the overlying

392 mixed layer (discussed in detail below).

393 Specifically, discrete in situ measurements taken over a depth profile across the

394 seawater-brine interface provide a context for calculating diffusive geochemical fluxes of

395 methane into the overlying water column. This approach has been used in numerous

396 studies for estimating the mass transfer (e.g., fluxes) of solutes from one region into

397 another. Brine pools such as AC601 are generally very quiescent in nature with fluid

398 advection playing a small role in controlling fluxes (Joye et al., 2005; Joye et al., 2009).

399 In these locations, where diffusion is the dominant mode of mass transfer, Fick's first law

400 is used to make first order estimates of the diffusive flux based on the measured

401 concentration gradients. The range of possible flux values is estimated based on error in

402 the spatial resolution of the gradient (i.e., since high precision positioning of the sampling

403 wand was not possible, we estimate the potential vertical position $\pm 10 \mathrm{~cm})$. Moreover, 
404 we adopted a value of $1.38 \mathrm{e}^{-5} \mathrm{~cm}^{2} \mathrm{~s}^{-1}$ for the diffusion coefficient of methane in seawater

405 adjusted for the average viscosity of the brine using the Stokes-Einstein relationship

406 (Mao and Duan, 2008; Sahores and Witherspoon, 1970).

407 Even with our lower-bound estimate of diffusive methane flux (1.1 mol m $\left.\mathrm{mr}^{-1}\right)$,

408 water column integrated methane oxidation rates (Fig. 4) measured directly above the

409 brine pool $\left(\sim 320 \mu \mathrm{mol} \mathrm{m} \mathrm{mr}^{-1}\right)$ indicate that only a very small fraction of methane

410 escaping the brine pool is biologically consumed in the overlying water column (0.02 to

$4110.03 \%$ ). While it is likely that lateral advection plays a large role in the disconnect

412 between brine pool flux and water column methane oxidation rates above the brine, upper

413 water column concentrations are nonetheless $>10$ times that of methane in equilibrium

414 with the atmosphere, confirming the transport of methane from depths $>2000 \mathrm{~m}$ into the

415 mixed layer which easily escapes, un-oxidized, into the atmosphere.

416 Our estimates of diffusive methane flux should be taken as a lower bound on flux

417 from environments such as Gulf of Mexico brine pools. They also underscore the value

418 of in situ measurement for constraining methane fluxes. For example, other studies

419 (Lapham et al., 2008; Schmidt et al., 2003) have modeled diffusive and/or advective

420 fluxes from brine seep environments by comparing profiles of a non-conservative solute

421 (e.g., methane) to conservative solutes (e.g., chloride, temperature). Using a 1-D reaction

422 transport model together with chloride and methane profiles, advective methane fluxes of

423 up to $2 \mathrm{~mol} \mathrm{~m}^{-2} \mathrm{yr}^{-1}$ were estimated from brine-influenced sediments characterized by a

424 strong advective flow (Lapham et al., 2008). However, these calculated fluxes were

425 based on methane concentrations from sediment cores that had degassed upon collection,

426 and were thus substantially lower than methane concentrations in situ. In another study, 
427 Solomon et al. (2008) employed osmotic samplers demonstrating that net seafloor

428 methane fluxes range from $0.89 \mathrm{~mol} \mathrm{~m}^{-2} \mathrm{yr}^{-1}$ from a mussel bed environment up to 29

$429 \mathrm{~mol} \mathrm{~m}^{-2} \mathrm{yr}^{-1}$ from a bacterial mat environment. Hereto, because methane concentrations

430 could not be reliably determined at in situ pressure and temperature, fluxes were

431 calculated assuming that porewater was in equilibrium with methane hydrate under in situ

432 conditions. However, others have shown that methane in sediments around hydrate can

433 be far from saturated (Lapham et al., pers. comm.), which would result in much lower

434 flux estimates. Future studies should aim to couple in situ methane measurements with

435 direct fluid flow measurements to better constrain the contribution of adjective flux to

436 water column methane flux.

\section{6. Summary and Conclusions}

438 Our calculated in situ AOM rates, using empirically derived rate constants, are

439 higher than those previously published by one to two orders of magnitude. The diffusive

440 flux was estimated to range as high $1.8 \mathrm{~mol} \mathrm{~m}^{-2} \mathrm{yr}^{-1}$ from the brine pool, while integrated

441 oxidation rates in the overlying $2000 \mathrm{~m}$ water column could only account for $0.32 \mu \mathrm{mol}$

$442 \mathrm{~m}^{-2} \mathrm{yr}^{-1}$. These data suggest that a very large component of the diffusive brine pool

443 methane flux escapes both aerobic and anaerobic oxidation in the water column above the

444 brine pool and may be released into the atmosphere (or at least subject to dispersion via

445 lateral advection). These first in situ measurements of methane concentration from a

446 brine pool using the ISMS enabled robust quantification of methane concentrations at in

447 situ conditions in these gas-charged brines and reflect the strong influence of the

448 surrounding hydrocarbon seep environments. Such integrated approaches - wherein

449 geochemical determinations are coupled with microbiological activity measurements - 
450 are the best means of providing a rigorous constraint on methane diffusive fluxes and

451 transformation rates. This will improve our understanding of the role that hydrocarbon

452 seeps may play in the delivery of methane into the ocean and ultimately the atmosphere.

453 


\section{Acknowledgements}

454 We are especially grateful to Stephane Hourdez for his immense help with this

455 instrument during this expedition. We are also grateful to Dr. Charles Fisher for his

456 support, as well as the captains and crew of the RV Ronald H. Brown and RV Atlantis.

457 Special thanks to the pilots and support staff of the DSV ALVIN and DSV JASON II from

458 Woods Hole Oceanographic Institution for help collecting and processing samples. An

459 extra thanks goes especially to Matthew Heinz and Tito Collasius for their assistance in

460 the machine shop. This research was supported by the U.S. Department of the Interior

461 Minerals Management Service, the National Oceanic and Atmospheric Administration,

462 the David and Lucile Packard Foundation, Harvard University, and the National Science

463 Foundation (MCB-0702504).

464

465 


\section{Figure captions}

466 Figure 1: Schematic of the in situ mass spectrometer. a) membrane inlet housing, b)

467 front end plate of titanium pressure housing, c) high pressure solenoid for isolation of 468 vacuum chamber, d) Alcatel ATH-31+ Turbo Pump, e) vacuum flight tube housing the

469 SRS Quadrupole RGA-200 including ion source, quadrupoles and detectors f) electronics

470 head for controlling and reading spectrometer signals g) KNF Neuberger roughing pump

471 model ANDC-84.3. Sample gas is continuously extracted across the membrane located

472 in (a) into the high vacuum system $(\mathrm{d}, \mathrm{g})$, ionized in (e) and analyzed by the detector and

473 electronics control unit housed in (f). The instrument is approximately $1 \mathrm{~m}$ in length.

475 Figure 2: a) Normalized response at m/z 15 over a range of hydrostatic pressure for 476 three example fluid temperatures and concentrations, $10^{\circ} \mathrm{C} 1160 \mu \mathrm{M} \mathrm{CH}_{4}$ (grey squares), $47722^{\circ} \mathrm{C} 800 \mu \mathrm{M} \mathrm{CH}_{4}$ (black triangles) and $14^{\circ} \mathrm{C} 180 \mu \mathrm{M} \mathrm{CH}_{4}$ (grey triangles). Responses to 478 pressure were experimentally fit under a wide range of temperatures and concentrations 479 (as in Bell et al 2007) with values of b' ranging between 0.02 to 0.24 and values of $\mathrm{k}$ 480 ranging between 0.84 to 0.94 . b) The response of $\mathrm{m} / \mathrm{z} 15$ (corrected for pressure effects 481 see Fig 2a) was linearly proportional to methane concentrations as measured 482 independently by gas chromatography (grey triangles) and as calculated after Duan et al 4832006 during high pressure calibration measurements (black circles).

485 Figure 3: Photo from the Pilot Cam of ROV Jason showing the starboard manipulator 486 reaching through the seawater/brine pool interface and sampling at a depth of 487 approximately $80 \mathrm{~cm}$. 
489 Figure 4: a) Depth profile of methane concentration and methane oxidation rates in the 490 water column above brine pool AC601. Note log scale. Open circles are concentration 491 measurements made from Niskin bottle samples, while black circles are those made in 492 situ using the ISMS. b) Close-up of seawater/brine pool interface and profile into the 493 brine fluid. Note the linear scale in contrast to panel a. Measured rates of anaerobic 494 methane oxidation (AOM) at two depths within the brine pool are shown. Note that 495 these, when corrected for in situ CH4 concentrations, these rates are 30-45 times higher. 496 Sulfate concentrations are depleted in the brine, consistent with its role in AOM. 


\section{References}

498 Bell, R.J., Short, R.T., van Amerom, F.H., Byrne, R.H., 2007. Calibration of an In Situ Membrane Inlet Mass Spectrometer for Measurements of Dissolved Gases and Volatile Organics in Seawater. Environmental Science \& Technology 41 (23), 8123-8128.

Camilli, R., Hemond, H.F., 2004. NEREUS/Kemonaut, a mobile autonomous underwater mass spectrometer. Trends in Analytical Chemistry 23 (4), 307-313.

Carini, S., LeCleir, G., Bano, N., Joye, S.B., 2005. Acitivity, abundance and diversity of aerobic methanotrophs in an alkaline, hypersaline lake (Mono Lake, CA, USA). Environmental Microbiology 7 (8), 1127-1138.

Childress, J.J., Arp, A.J., Fisher Jr., C.R., 1984. Metabolic and blood characteristics of the hydrothermal vent tubeworm Riftia pachyptila. Marine Biology 83, 109-124.

Collett, T., Kuuskraa, V., 1998. Hydrates contain vast store of world gas resources. Oil Gas Journal 96 (19), 90-95.

Devol, A.H., 1983. Methane oxidation rates in the anaerobic sediments of Saanich Inlet. Limnology and Oceanography 28, 738-742.

Dickens, G.R., 2003. Rethinking the global carbon cycle with a large, dynamic and microbially mediated gas hydrate capacitor. Earth and Planetary Science Letters $213(3-4), 169-183$.

Duan, Z., Mao, S., 2006. A thermodynamic model for calculating methane solubility, density and gas phase composition of methane-bearing aqueous fluids from 273 to 523K and from 1 to 2000 bar. Geochimica et Cosmochimica Acta 70 (13), 33693386.

Fisher, C.R., Roberts, H., Cordes, E.E., Bernard, B., 2007. Cold seeps and associated communities of the Gulf of Mexico Oceanography 20 (4), 118-129.

Girguis, P.R., Childress, J.J., Freytag, J.A., Klose, K., Stuber, R., 2002. Effects of metabolite uptake on proton-equivalent elimnation by two species of deep-sea vestimentiferan tubeworms, Riftia pachyptila and Lamellibrachia luymesi. Journal of Experimental Biology 205, 3005-3006. 
Girguis, P.R., Lee, R.W., Childress, J.J., Pospesel, M., Desaulniers, N.T., Zal, F., Felbeck, H., 2000. Fate of nitrate acquired by the hydrothermal vent tubeworm Riftia pachyptila. Applied and Environmental Microbiology 66 (7), 2783-2790.

Girguis, P.R., Orphan, V.J., Hallam, S.J., DeLong, E.F., 2003. Growth and methane oxidation rates of anaerobic methanotrophic archaea in a continuous flow reactor bioreactor. Applied and Environmental Microbiology 69, 5492-5502.

Hemond, H.F., 1991. A Backpack-portable mass spectrometer for measurement of volatile compounds in the environment. Review of Scientific Instruments 62 (6), 1420-1425.

Johnson, R., Cooks, R., Allen, T., Cisper, M., Hemberger, P., 2000. Membrane introduction mass spectrometry: Trends and applications Mass Spectrometry Reviews 19, 1-37.

Joye, S.B., Boetius, A., Orcutt, B.N., Montoya, J.P., Schulz, H.N., Erickson, M.J., Lugo, S., 2004. The anaerobic oxidation of methane and sulfate reduction in sediments from Gulf of Mexico cold seeps. Chemical Geology 205, 219-238.

Joye, S.B., Connell, T.L., Miller, L.G., Oremland, R.S., Jellison, R.S., 1999. Oxidation of ammonia and methane in an alkaline, saline lake. Limnology and Oceanography 44 (1), 178-188.

Joye, S.B., MacDonald, I.R., Montoya, J.P., Peccini, M., 2005. Geophysical and geochemical signatures of Gulf of Mexico seafloor brines. Biogeosciences 2, 295309.

Joye, S.B., Samarkin, V., Orcutt, B.N., MacDonald, I.R., Hinrichs, K.-U., Elvert, M., Teske, A., Lloyd, K.G., Lever, M.A., Montoya, J.P., Meile, C., 2009. Metabolic variability in seafloor brines revealed by carbon and sulfur cycling. Nature Geosciences 2, 349-354.

Kaiser, J., Reuer, M.K., Barnett, B., Bender, M.L., 2005. Marine productivity estimates from continuous $\mathrm{O} 2 / \mathrm{Ar}$ ratio measurements by membrane inlet mass spectrometry. Geophysical Research Letters 32, doi:10.1029/2005GL23459.

Kana, T.M., Darkangelo, C., Hunt, M.D., Oldham, J.B., Bennett, G.E., Cornwell, J., 1994. Membrane Inlet Mass Spectrometer for Rapid High-Precision 
Determination of N2, O2, Ar in Environmental Water Samples. Analytical Chemistry 66, 4166-4170.

558 Kana, T.M., Sullivan, M.B., Cornwell, J.C., Groszkowski, K.M., 1998. Denitrification in estuarine sediments determined by membrane inlet mass spectrometry. Limnology and Oceanography 43 (2), 334-339.

Kennicutt, M.C., II, Brooks, J.M., Denous, G., 1988. Leakage of deep, reservoired

Kvenvolden, K., 1993. Gas hydrates - geological perspective and global change. Reviews of Geophysics 31 (2), 173-187.

Kvenvolden, K., Lorensen, T.D., 2008. A global inventory of natural gas hydrate occurence. http://walrus.wr.usgs.gov/globalhydrate/index.html.

Lapham, L.L., Alperin, M., Chanton, J., Martens, C.S., 2008. Upward advection rates and methane fluxes, oxidation, and sources at two Gulf of Mexico brine seeps. Marine Chemistry 112, 65-71.

Lloyd, D., Davies, K.J., Boddy, L., 1986. Mass spectrometry as an ecological tool for in situ measurement of dissolved gases in sediment systems. FEMS Microbiology Ecology 38, 11-17.

Lloyd, D., Thomas, K.L., Hayes, A., Hill, B., Hales, B.A., Edwards, C., Saunders, J.R., Ritchie, D.A., Upton, M., 1998. Micro-ecology of peat: Minimally invasive analysis using confocal laser scanning microscopy, membrane inlet mass spectrometry and PCR amplification of methanogen-specific gene sequences. FEMS Microbiology Ecology 25, 179-188.

MacDonald, I.R., Reilly, J., Guinasso, J., Brooks, J.M., Carney, R., Bryant, W.A., Bright, T.J., 1990. Chemosynthetic mussels at a Brine-filled pockmark in the Northern Gulf of Mexico. Science 248 (4959), 1096-1099. 
MacDonald, I.R., Sager, W., Peccini, M., 2003. Association of gas hydrate and chemosynthetic fauna in mounded bathymetry at mid-slope hydrocarbon seeps: Northern Gulf of Mexico. Marine Geology 198, 133-158.

Orcutt, B.N., Boetius, A., Elvert, M., Samarkin, V., Joye, S.B., 2005. Molecular biogeochemistry of sulfate reduction, methanogenesis and the anaerobic oxidation of methane at Gulf of Mexico cold seeps. Geochimca et Cosmochimica Acta 69 (17), 4267-4281.

Oren, A., 2002. Diversity of halophilic microorganisms: environments, phylogeny, physiology, and applications. Journal of Industrial Microbiology and Biotechnology 28, 56-63.

Reeburgh, W.S., 1980. Anaerobic methane oxidation: Rate depth distribution in Skan Bay sediments. Earth and Planetary Science Letters 47 (3), 345-352.

Reeburgh, W.S., 2007. Oceanic Methane Biogeochemistry. Chemical Reviews 107 (2), 486-513.

Roberts, H., Carney, R., 1997. Evidence of episodic fluid, gas, and sediment venting on the northern Gulf of Mexico continental slope Economic Geology 92, 863-879.

Roberts, H., Fisher, C.R., Bernard, B., Brooks, J.M., Bright, M., Carney, R., Cordes, E., Hourdez, S., Hunt, J.J., Joye, S.B., 2007. ALVIN explores the deep northern Gulf of Mexico Slope. Eos Transactions 88, 341-342.

Schmidt, M., Botz, R., Faber, E., Schmitt, M., Poggenburg, J., Garbe-Schönberg, D., Stoffers, P., 2003. High-resolution methane profiles across anoxic brine-seawater boundaries in the Atlantis-II, Discovery, and Kebrit Deeps (Red Sea). Chemical Geology 200, 359-375.

Sloan, L.C., Walker, J.C., Moore, J., TC, Rea, D.K., Zachos, J.C., 1992. Possible methane-induced polar warming in the early Eocene Nature 357, 320-322.

Solomon, E.A., Kastner, M., Jannasch, H., Robertson, G., Weinstein, Y., 2008. Dynamic fluid flow and chemical fluxes associated with a seafloor gas hydrate deposit on the northern Gulf of Mexico slope. Earth and Planetary Science Letters 270, 95105.

Suess, E., Torres, M., Bohrmann, G., Collier, R., Greinert, J., Linke, P., Rehder, G., Trehu, A., Wallman, K., Zuleger, E., 1999. Gas hydrate destablization: Enhanced 
616 dewatering, benthic material turnover and large methane plumes at the Cascadia 617 convergent margin. Earth and Planetary Science Letters 170, 1-15.

618 Tortell, P., 2005a. Small-scale heterogeneity of dissolved gas concentrations in marine 619 continental shelf waters. Geochemistry, Geophysics, Geosystems 6, Q11M04.

620 Tortell, P.D., 2005b. Dissolved gas measurements in oceanic waters made by membrane 621 inlet mass spectrometry. Limnology and Oceanography: Methods 3, 24-37.

622 TValentine, D.L., Blanton, D., Reeburgh, W.S., Kastner, M., 2001. Water column 623 methane oxidation adjacent to an area of active hydrate dissociation, Eel River 624 Basin. Geochimca et Cosmochimica Acta 65, 2633-2640.

625 Zachos, J.C., Pagani, M., Sloan, L., Thomas, E., Billups, K., 2001. Trends, rhythms and 626 aberrations in global climate 65 Ma to Present. Science 292 (5517), 686-674. 


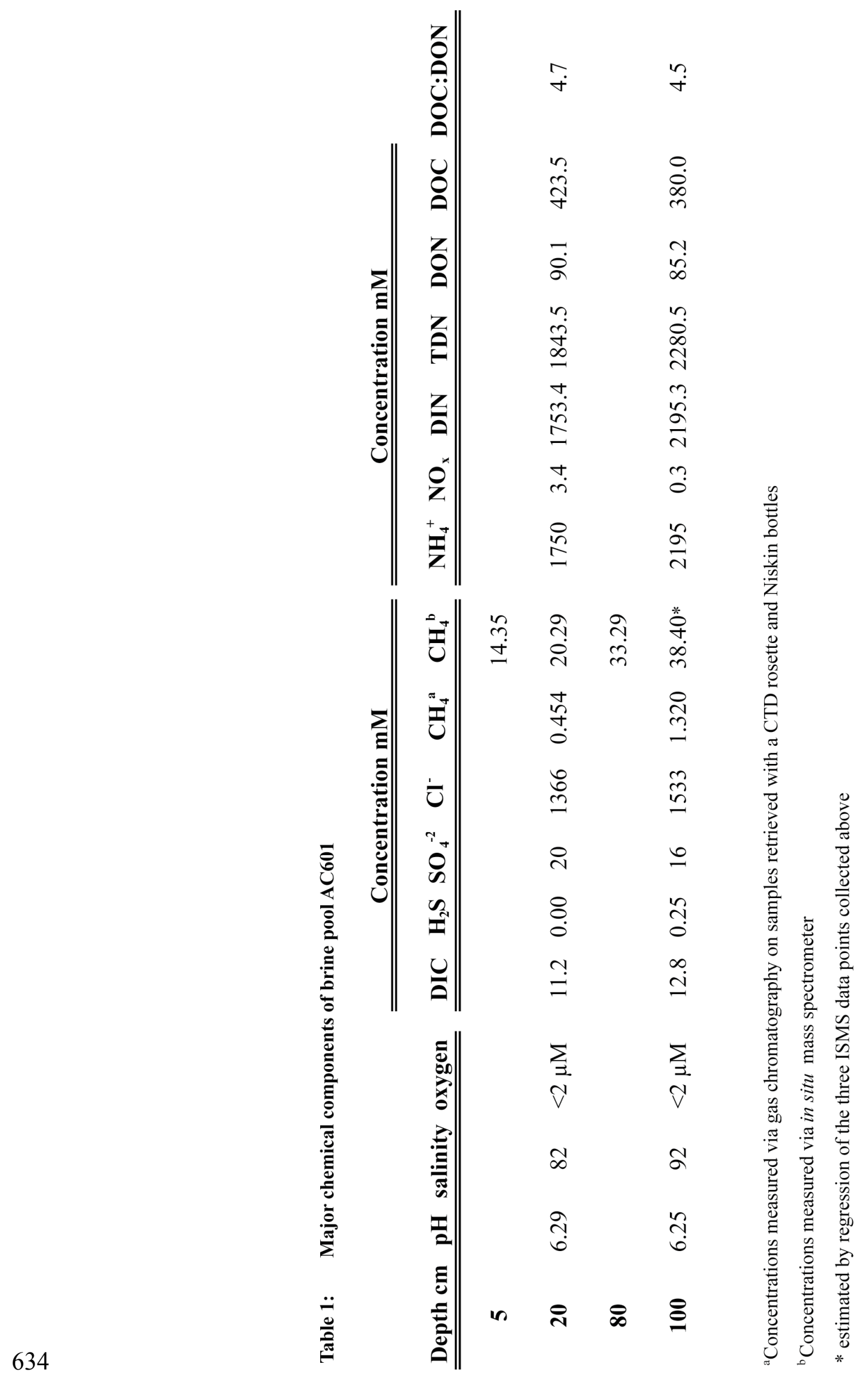


635

636

637

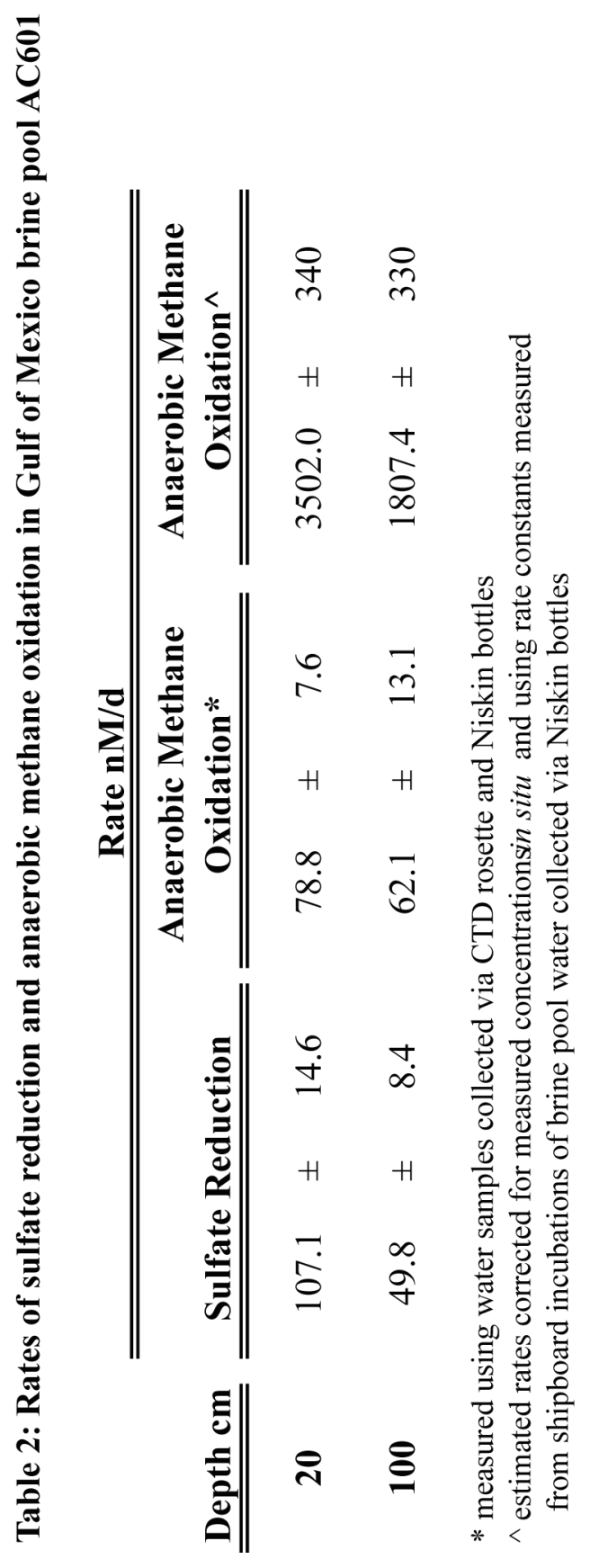

639

640

641

642

643 
643

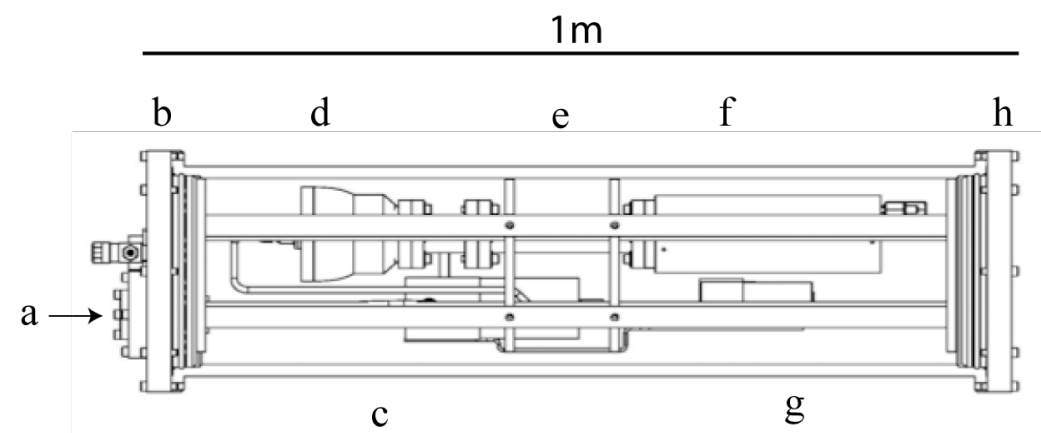

644 Wankel Figure 1

645

646

647

648

649 

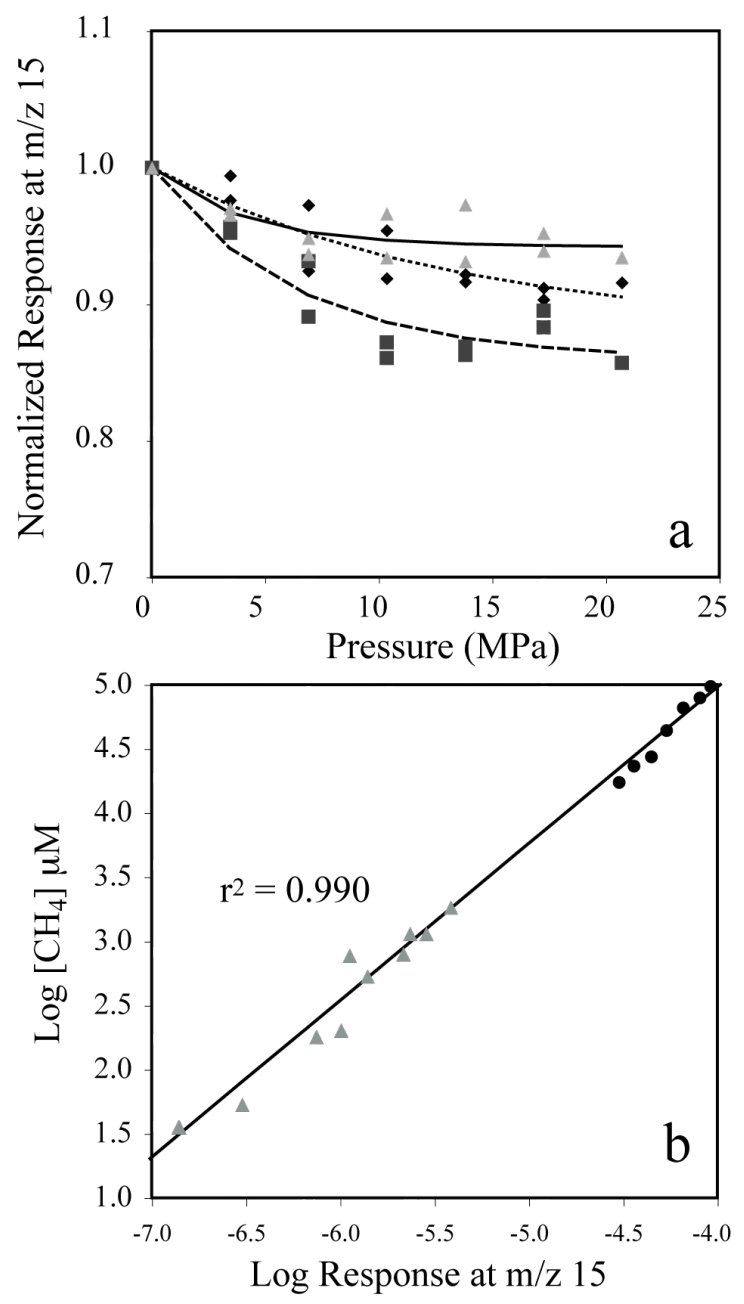
Wankel Figure 3

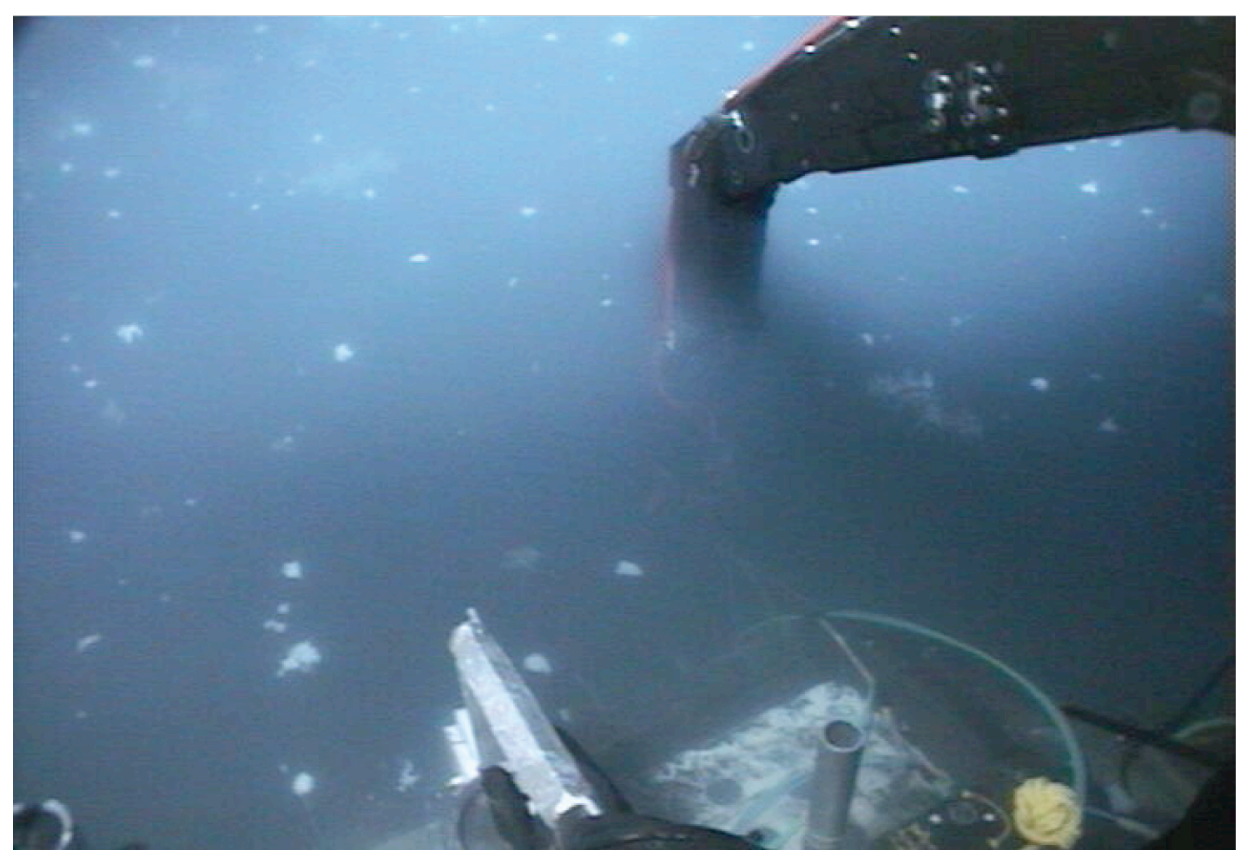




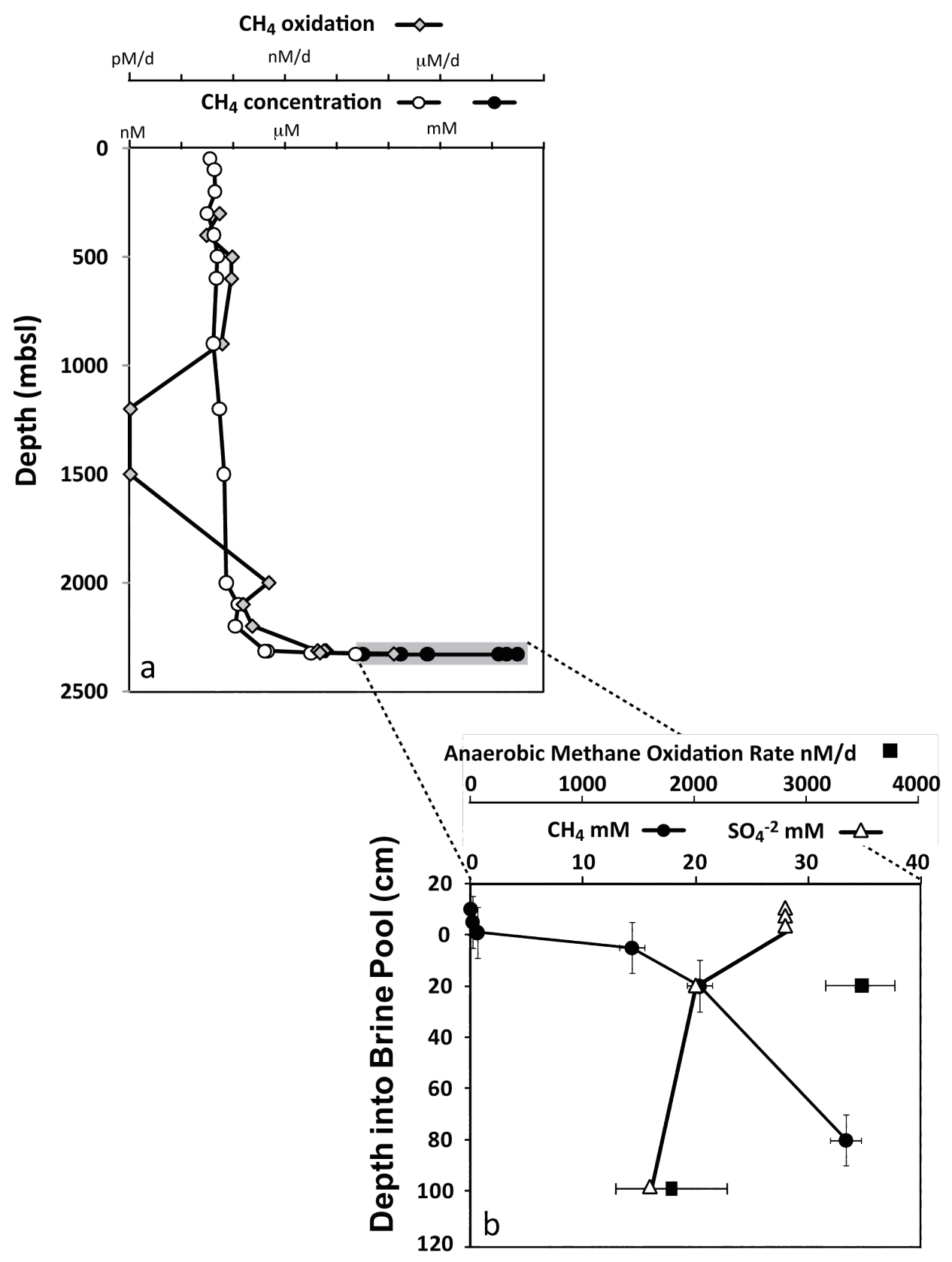

